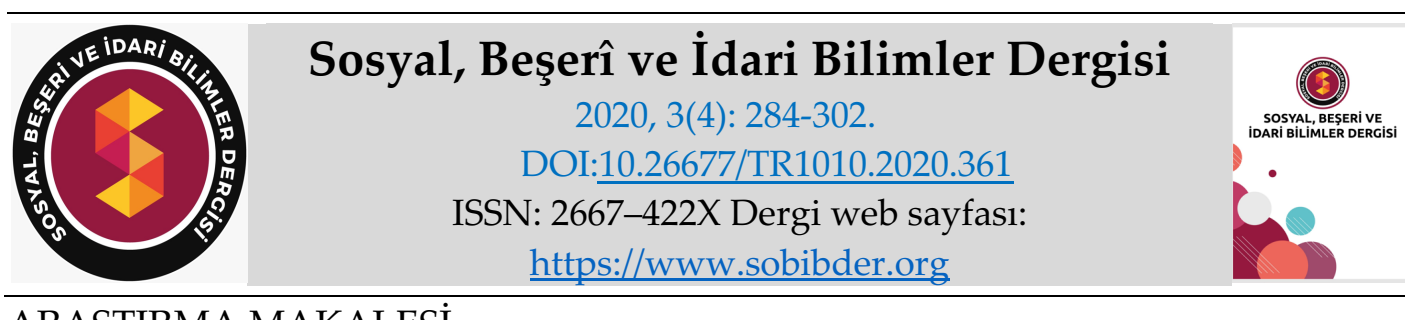

ARASTTIRMA MAKALESI

\title{
Okul Müdürlerinin Paternalist Liderlik Davranışlarının Okul Kültürüne Etkisi
}

Dr. Öğr. Üyesi Mustafa ÖZGENEL, İstanbul Sabahattin Zaim Üniversitesi, Eğitim Fakültesi, İstanbul, e-posta: mustafa.ozgenel@izu.edu.tr ORCID: https://orcid.org/0000-0002-7276-4865

İsmail Eray DURSUN, Silivri Kaymakamlığı, Gümüşyaka Anadolu Lisesi Müdürlüğü, İstanbul, e-posta: ismail.eray.dursun@gmail.com

ORCID: https://orcid.org/0000-0002-6420-7487

Öz

$\mathrm{Bu}$ araştırmanın amacı, öğretmenlerin algılarına göre okul müdürlerinin paternalist liderlik davranışlarının okul kültürünü ne düzeyde etkilediğini saptamaktır. Araştırmanın örneklemini, 2018-2019 eğitim öğretim yılında İstanbul ili Beylikdüzü ilçesine bağlı farklı okul kademelerinde görev yapan 420 öğretmen oluşturmaktadır. Araştırmada ilişkisel tarama modeli kullanılmıştır. Araştırmada, Dağlı ve Ağalday (2017) tarafından geliştirilen "Okul Müdürlerinin Paternalist Liderlik Davranışları Ölçeği" ile Terzi (2005) tarafından geliştirilen "Okul Kültürü Ölçeği" kullanılmıştır. Veriler t-testi, tek yönlü varyans analizi (ANOVA), korelasyon ve basit regresyon analizleri ile incelenmiştir. Araştırma sonucunda okul müdürlerinin öğretmenler tarafından algılanan paternalist liderlik davranışlarının "orta düzeyde" olduğu belirlenmiştir. Erkek öğretmenler okul müdürlerini kadın öğretmenlere göre daha fazla babacan lider olarak görmektedir. Okul müdürlerinin paternalist liderlik davranışları ile bürokratik okul kültürü arasında pozitif yönde ve düşük düzeyde ilişki olduğu; diğer okul kültürü türleri ile babacan liderlik davranışları arasında ise anlamlı bir ilişki olmadığı ortaya çıkmıştır. Başka bir ifadeyle okul müdürlerinin paternalist liderlik davranışları bürokratik okul kültürünü olumlu yönde ve düşük düzeyde yordadığı sonucuna ulaşılmıştır.

* Bu çalışma, İsmail Eray DURSUN'un Dr. Mustafa ÖZGENEL danışmanlığında yürütülen yüksek lisans tezinden üretilmiştir. Ayrıca bu çalışma, 2. Uluslararası Eğitimde Yeni Arayışlar Kongresi'nde sözlü bildiri olarak sunulmuştur.

Anahtar Kelimeler: Okul Kültürü, Liderlik, Paternalist Liderlik, Okul Müdürü, Öğretmen.

Makale Gönderme Tarihi: 24.01.2020

Makale Kabul Tarihi: 05.04.2020

\section{Önerilen Atıf:}

Özgenel, M. ve Dursun, İ. E. (2020). Okul Müdürlerinin Paternalist Liderlik Davranışlarının Okul Kültürüne Etkisi, Sosyal, Beşeri ve İdari Bilimler Dergisi, 3(4): 284-302.

(C) 2020 Sosyal, Beşerî ve İdari Bilimler Dergisi. 


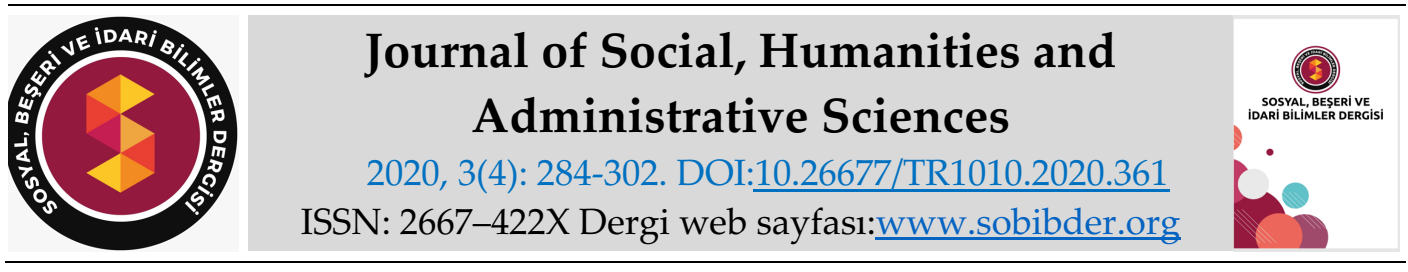

RESEARCH PAPER

\title{
The Effect of Paternalistic Leadership Behaviors of School Principals on School Culture
}

Assistant Prof. Dr. Mustafa ÖZGENEL, İstanbul Sabahattin Zaim University, Faculty of Education, İstanbul, e-mail: mustafa.ozgenel@izu.edu.tr

ORCID: https://orcid.org/0000-0002-7276-4865

İsmail Eray DURSUN, Silivri District Governorship, Gümüşyaka Anatolian High School Directorate, İstanbul, e-mail: ismail.eray.dursun@gmail.com

ORCID: https://orcid.org/0000-0002-6420-7487

\begin{abstract}
The purpose of this study is to determine to what extent the school principals' paternalist leadership behavior affects the school culture according to the perceptions of teachers working in schools. The sample of the study consists of 420 teachers working in different types of schools in Beylikdüzü district of Istanbul province in 2018-2019 academic year. Relational survey model was used in the research. In the research, "Paternalist Leadership Behaviors Scale of School Principals" developed by Dağlı and Ağalday (2017) and "School Culture Scale" developed by Terzi (2005) were used. The data were analyzed by t-test, one-way variance analysis (ANOVA), correlation and simple regression analysis. As a result of the research, it has been determined that the paternalist leadership behaviors perceived by the teachers are "moderate". Male teachers see school principals as more fatherly leaders than female teachers. There is a positive and low-level relationship between the paternalist leadership behaviors of school principals and bureaucratic school culture; however, there was no significant relationship between other school culture types and paternalistic leadership behaviors. In other words, it has been concluded that school principals predict paternalist leadership behaviors positively and at a low level.
\end{abstract}

Keywords: School Culture, Leadership, Paternalistic Leadership, School Principal, Teacher.

Received: 24.01.2020

Accepted: 05.04.2020

Suggested Citation:

Özgenel, M. and Dursun, İ. E. (2020). The Effect of Paternalistic Leadership Behaviors of School Principals on School Culture, Journal of Social, Humanities and Administrative Sciences, 3(4): 284-302. (C) 2020 Sosyal, Beşerî ve İdari Bilimler Dergisi. 


\section{Gíriş}

Kültür, tarihte tarım, yerleşik hayat ve düzen anlamlarında kullanılmıştır. Fiil olarak "bakmak" ve "yetiştirmek" anlamına gelen Latince kökenli colere ve cultura kelimelerinden türediği ileri sürülmektedir (Tutar, 2016). İlk olarak on yedinci yüzyılda Voltaire'in kültür kavramına çalışmalarında yer vermesinin ardından kültür ile ilgili günümüze kadar sayısız tanım üretilmiştir. Sosyal yaşamın her alanını etkileyen kültürün öz kaynaklarımızda sistemli bir şekilde yer almasını sağlayan Ziya Gökalp'tir. Kültürü milli, soyut değer ve somut eserler bütünü olarak gören Gökalp, "yalnız bir milletin dini, ahlaki, hukuki, akli, estetik, lisani, iktisadi ve fenni hayatlarının ahenkli bir bütünüdür" şeklinde ifade etmiştir (Tutar, 2016).

Toplumun temeli kültürdür. İlkel toplumdan modern topluma her toplumun kültürü vardır (Coşgun, 2012). Şişman'a (2002) göre kültür, durağan değil; aksine dinamiktir, üyeleri tarafından sürekli yenilenir, gelişir ve zamanın koşullarından etkilenerek yeni halini alarak sonraki nesillere aktarılır. Bir toplumun yaşayış biçimi, bireyin edindiği sosyal miras, düşünme ve hissetme biçimi, doğada karşılaşana karşı insanoğlunun oluşturduğu her şeydir (Şişman, 1994). Kültürü, örgüt bağlamında ele aldığımızda ise örgüt kültürü ile ilgili çok fazla tanım yapılmakta ve değişik yollarla ifade edilmektedir (Günbayı, 2014; Sökmen, 2013; Şişman, 2002; Terzi, 2000). Schein'e göre (2004) kültür, örgütleri sarmalayan, yaşama ve gelişme süreçlerini etkileyen en önemli etmendir. Örgüt kültürü örgütün gerçek kimliğini ortaya çıkaran bir değerler dizisidir. Bu değerler dizisi üyelere çözüm önerileri, karşılaşan problemleri tanıma ve aşma yolları ve örgütte nasıl davranacaklarına dair yol haritası sunar (Çelik, 2002). Örgüt kültürü, “bir örgütün içindeki insanların davranışlarını yönlendiren normlar, davranışlar, değerler, inançlar ve alışkanlıklar sistemidir" (Dinçer, 1992: 271).

Örgüt kültürü ile liderler arasında önemli bağ vardır. Örgüt kültürünün oluşmasında etkili liderler zemin hazırlar. Örgütün kurucusu kadar örgüt liderinin de kültür üzerinde etkisi olduğu ifade edilmektedir (Akıncl, 1998). Başka bir deyişle liderlerin ilke ve değerlerini, örgütün kültüründe bulmak mümkündür (Schein, 2004). Zira liderler, örgütün yapı ve teknoloji gibi somut ve yapısal tarafını oluşturmakla birlikte, diğer taraftan örgütün sembollerinin, ekolünün, efsane ve törenlerinin oluşturulmasında da etkilidirler (Akıncı, 1998). Liderlik: Bireyselde rehberlik ve motive etme, grupta takım birliği ve sorunları çözme, örgütselde kültür oluşturma olmak üzere üç farklı şekilde uygulanır. Liderin etkileyiciliği büyük ölçüde oluşturacağı bu örgütsel kültüre bağlanmaktadır (Akıncl, 1998).

Lider kökü Anglosakson kelimelerden olan, "seyahat etmek" ve "gitmek" anlamına gelen "Lead" eyleminden gelir. Anglosaksonlar bu kelimeye "bu yolda giden" "seyahat eden" anlaminı yüklemişlerdir (Zel, 2011). Lider kelimesi ilk 1755 yılında İngilizce bir sözlükte Samuel Johnson tarafından "önden giden kimse" olarak yer alırken liderlik kelimesi ise 1828 yılında Amerika'da basılan bir sözlükte "liderin durumu" olarak yer almıştır. Türkçemizde de "önder" olarak yer alan lider kelimesinin çok fazla kullanılmadığı bilinmektedir (İbicioğlu, Özmen ve Taş, 2009: 3).

Lider, grup üyeleri tarafından tanımlanan ve kabul gören, grup performansında en etkili değişikliği yaratan, üye etkileşimini tesis eden kişidir (Fieldler, 1967). Liderlik ise Önen ve Kanayran'a (2015) göre hedefe ulaşmak için bir amaç doğrultusunda toplanan bireyleri elde edebilme gayretidir. Aslan'a (2013) göre ise Zaleznik, liderliği başkalarının fikirlerini ve eylemlerini etkileme gücü olarak görmektedir.

Liderlik tanımlaması hem zor bir kavram hem de çok fazla tanım içermekte, liderliği kendine göre yorumlama çabaları birçok liderlik stilinin ortaya çıkmasına sebep olmuştur. Bu liderlik stillerinden bir tanesi de paternalist (babacan) liderliktir (Çelik, 2007). Paternalist liderlik kavramı bilimsel açıdan ilk kez 1960'lı yıllarda Dr. Silin'in araştırmalarında yer aldığı görülmektedir. 
Tayvan' da yaptığı araştırmalarında paternalizmin, ahlaki standartlar ve otorite gücü olarak Batı liderlik türlerinden farklılaştığını keşfeden Silin, yöneticilerin öğretici ve ahlaki liderlik, merkezi otorite, astlarıyla mesafeli olma gibi davranışlar sergilediklerini gözlemlemiştir (Uçar 2019; Gerçek, 2018; Köksal, 2011b). Fahr ve Cheng'e (2000) göre paternalist liderlik sıkı bir disiplin ve otoriteyi, baba şefkati ve ilgi ile birleştiren bir liderlik türüdür. Paternalist lider, astına karşı babaevlat ilişkisine benzer bir tutum sergilemektedir (Arslan, 2016). Lider ile örgüt üyeleri arasındaki ilişki incelendiğinde lider adeta astlarına bir baba gibi ve örgüt içi aile atmosferi yaratma çabası olduğu görülmektedir. Lider astlarının iş hayatı içinde ve dışında karşılaşabileceği problemler ile ilgilenir. Ayrıca astlarının kutlama ve cenaze törenleri gibi önemli zamanlarında yanlarında olur (Erkuş, Tabak ve Yaman, 2010). Paternalizme hakim kültürlerde astlarına karşı koruma eğiliminde olan liderler, karşılığında sadakat beklemektedirler (Aycan, 2001).

Kolektivist toplumlarda geçerli sayılan bu durum birey odaklı kültürlerde liderin astının özel hayatı ve ailevi konulara müdahale etmesi istenen bir durum değildir. Ülkemizin de kolektivist kültür karakterine sahip bir toplum olduğu düşünüldüğünde, paternalizm örgütler için önem arz ettiği düşünülmektedir (Köksal, 2011a).

Paternalist liderlik; otorite, yardımseverlik ve ahlaki boyut olmak üzere üç boyutta incelendiği görülmektedir (Fahr ve Cheng, 2000; Aycan, 2006). Yardımseverlikte, liderler örgütte çalışan bireylerin mutluluk ve iyiliğini sağlamak için tüm yaşamları boyunca yaşamlarının her anında onlarla alakadar olmakta iken otoriter lideri, karşı konulamaz mutlak liderlik olarak tanımlamıştır, astlar sıkı sıkıya kontrol altındadır ve sorgusuz sualsiz itaat etme zorunluluğunu ve baskısını hissetmektedirler (Erben ve Güneşer, 2008). Ahlaki liderlikte, üstün kişisel erdemi, öz disiplini ve bencil olmamayı içermektedir. Kişisel yönetim ve öz denetim olarak karakterize edilmektedir ve altında astların saygısını kazanma amacı bulunmaktadır (Şendoğdu ve Erdirençelebi, 2014).

Günümüz çağdaş okul müdürlerinin modernist düşünceden uzak, personeline verdiği talimatlara uyup uymadığını teftiş eden yöneticiler değil öğretimi planlayan, yaratıcılıkların önünü açan, personelini destekleyen ve vizyon sahibi olması beklenmektedir (Gümüşeli, 2001). Paternalist lidere, babacan tarzı ve iş ortamında uyguladığı ailevi hava sebebiyle olumlu yaklaşılırken, bu tip liderlerin bazı çalışanlara yanlı davranabileceği ve kendine daha çok sadakatli olarak değerlendirdikleri çalışanlara imtiyazlı yaklaşacağı da düşünülmektedir. Paternalist lider, örgüt üyelerine karşı gerekli ilgiyi göstermediğinde otoriter bir kimliğe dönüşmekte ve örgüt tarafından eleştiri alabilmektedir (Erben, 2004).

Liderlik ile ilgili çalışmalar kültür ile yakından ilişkili olarak ele alınmaya başlanmıştır. Son 50 yılda kültürlerarası liderlik çalışmaları araştırmacıların dikkatini çekmiş fakat çoğu liderlik yaklaşımları batı kökenli olduğu görülmüştür. Batıların aksine, doğu kültürlerinde çokça rastlanan paternalist liderler, astlarına yakın ilgi gösteren onları ailesi gibi gören otoriter ataerkil bir kimliğe sahiptirler. Doğu ülkelerin kültürlerine daha uygun olan bu liderlik yaklaşımı son yıllarda Türkiye'de de araştırmalara konu olmaya başlamış ve örgüt yönetimlerinde etkili bir yönetim aracı olabileceğini göstermiştir (Gerçek, 2018). Bu bağlamda literatür incelendiğinde paternalist liderlik ile örgütsel vatandaşlık ve örgütsel sinizm (Mete ve Serin, 2015), iş doyumu (Cerit, 2012), örgütsel sinizm (Arslan, 2016), sınıf öğretmenlerinin paternalist liderlik algıları (Cerit, Özdemir ve Akgün, 2011), örgütsel özdeşleşme (Korkmaz, Gökdeniz ve Zorlu, 2018) arasındaki ilişkiyi ele alan araştırmalar bulunmaktadır. Ayrıca paternalist liderliğin; örgütsel özdeşleşme, iş performansı ve işten ayrılmaya (Yaman, 2011), tükenmişlik, işe bağlllık, mobbing ve organizasyona (Yurdun, 2011), psikolojik güçlenmeye (Demirer, 2012), duygusal tacize (Şahin, 2015), iş tatminine (Yardımcı, 2010), yaratıcı katılıma (Kurt, 2013), örgütsel adalete (Köksal, 2011b) etkisini ortaya koyan çalışmalara da rastlanılmaktadır. 
Okul kültürü ile ilgili literatür incelendiğinde ise okul kültürünün çevreye tanıtılması (Özdemir, 2006), ilköğretim okullarında okul kültürü algısı (Esinbay, 2008), okul kültürü ve öğretmenlerin değer sistemi (Fırat, 2007), okul kültürü ile örgütsel sağllk ilişkisi (Özdemir, 2013), örgütsel bağl1lı̆̆1 (Sezgin, 2010), müdürlerin güç kullanma stilleri (Koşar ve Çalık, 2011), müdürlerin iletişim becerileri (Şimşek, 2003), dönüşümcü ve sürdürümcü liderlik stilleri (Şahin, 2003), vizyoner liderlik (Koçman, 2005) arasındaki ilişkiyi tespit etmeye yönelik birçok çalışma yapıldığı görülmektedir. Cesur, Erkilet ve Taylan (2015) üniversite çalışanlarının paternalist liderlik ile okul kültürü algılarını incelemiştir. Ancak alanyazında farklı okul kademelerinin (anaokul, ilkokul, ortaokul ve lise) okul kültürü ile paternalist liderlik arasındaki ilişkisinin incelendiği çalışmaların sınırlı sayıda olduğu belirlenmiştir. Bundan dolayı araştırmada okul müdürlerinin paternalist liderlik yaklaşımının okul kültürüne etkisinin olup olmadığını belirlemek amaçlanmıştır. Bu genel amaç çerçevesinde aşağıdaki alt amaçlara cevap aranmıştır:

1. Okul müdürlerinin öğretmenler tarafından algılanan paternalist liderlik davranışları ve öğretmenlerin okul kültürü algıları ne düzeydedir?

2. Okul müdürlerinin öğretmenler tarafından algılanan paternalist liderlik davranışları ve öğretmenlerin okul kültürü algıları demografik değişkenlere göre (cinsiyet, eğitim düzeyi, yaş, okul türü, şu an ki müdürle çalışma yılı) anlamlı farklılık göstermekte midir?

3. Okul müdürlerinin öğretmenler tarafından algılanan paternalist liderlik davranışları ile okul kültürü arasında anlamlı bir ilişki var mıdır?

4. Okul müdürlerinin öğretmenler tarafından algılanan paternalist liderlik davranışları, okul kültürünü yordamakta mıdır?

\section{YÖNTEM}

Bu bölümde araştırmanın modeli, evren-örneklem, veri toplama araçları, verilerin toplanması ve verilerin analizi ile ilgili bilgiler verilmiştir.

\section{Araştırmanın Modeli}

$\mathrm{Bu}$ araştırma, öğretmen algılarına göre müdürlerin paternalist liderlik davranışlarının okul kültürünü oluşturmadaki etkisini belirlemeyi amaçlayan bir araştırmadır. Araştırmada tarama türlerinden ilişkisel tarama modeli kullanılmıştır. İlişkisel tarama modeli, iki veya daha fazla değişken arasındaki ilişkileri inceleyerek mevcut durumların daha iyi anlaşılmasını sağlar (Büyüköztürk, Çakmak, Akgün, Karadeniz ve Demirel, 2015: 23-24).

\section{Evren ve Örneklem}

Çalışmanın evreni, İstanbul ili Beylikdüzü ilçesinde 4 anaokul, 20 ilkokul, 19 ortaokul ve 17 ortaöğretim kurumunda görev yapmakta olan toplam 2.630 kadrolu öğretmenden oluşmaktadır (www.beylikduzu.meb.gov.tr). Araştırmada kolay ulaşılabilir örnekleme yöntemi kullanılmıştır. Kolay ulaşılabilir örnekleme yöntemi, maddiyat, işgücü ve zaman kaybının önlemesi açısından meydana çıkabilecek sinırlılıklar sebebiyle örneklemin uygulaması ve ulaşılmasının kolay birimlerden belirlenmesidir (Büyüköztürk, Çakmak, Akgün, Karadeniz ve Demirel, 2015). Öğretmenlere ulaşabilmek amaciyla belirlenen 3 anaokulu, 13 ilkokul, 15 ortaokul ve 13 ortaöğretim kurumuna toplamda 600 ölçek dağıtılmış olup 431 ölçek geri toplanmıştır. 431 ölçekten hatalı ve eksik belirlenen 11 ölçek elenmiş, kalan 420 ölçek değerlendirmeye alınarak 
örneklemi oluşturmuştur. Araştırmaya katılan öğretmenlere ilişkin demografik bilgiler Tablo 1 'de verilmiştir.

\begin{tabular}{|c|c|c|c|}
\hline Özellik & Gruplar & Siklık & $(\%)$ \\
\hline \multirow{2}{*}{ Cinsiyet } & Erkek & 139 & 33,1 \\
\hline & Kadın & 281 & 66,9 \\
\hline \multirow{2}{*}{ Öğrenim Durumu } & Lisans & 350 & 83,3 \\
\hline & Lisansüstü & 70 & 16,7 \\
\hline \multirow{4}{*}{ Yaş } & 30 yaş ve altı & 131 & 31,2 \\
\hline & $31-40$ & 179 & 42,6 \\
\hline & $41-50$ & 84 & 20,0 \\
\hline & 51-üstü & 26 & 6,2 \\
\hline \multirow{4}{*}{ Okul Türü } & Anaokulu & 26 & 6,2 \\
\hline & İlkokul & 93 & 22,1 \\
\hline & Ortaokul & 176 & 41,9 \\
\hline & Ortaöğretim & 125 & 29,8 \\
\hline \multirow{4}{*}{$\begin{array}{l}\text { Şuan ki Müdürle } \\
\text { Çalışma Yılı }\end{array}$} & $0-2$ & 224 & 53,3 \\
\hline & $3-4$ & 101 & 24,0 \\
\hline & $5-6$ & 71 & 16,9 \\
\hline & 7-üstü & 24 & 5,7 \\
\hline Toplam & & 420 & 100,0 \\
\hline
\end{tabular}

Tablo 1'de görüldüğü üzere araştırmaya 420 öğretmen katılmış olup, öğretmenlerin yüzde 66.9'u kadın, \% 33.1'i ise erkektir. Öğretmenlerin \%83.3'ü lisans mezunuyken \%16.7 si lisansüstü seviyesinde eğitim görmüştür. Öğretmenlerin, \% 31.2 si 30 yaş altı, \% 42.6's1 31-40, \% 20.0 si 4140 ve \% 6.2'si 51 ve üstü yaş seviyesindedir. Okul kademesi açısından ise en fazla ortaokulda görev yapan öğretmen bulunurken (\%41.9), bunu sırasıyla ortaöğretim (\%29.8), ilkokul (\%22.1) ve anaokulu (\%6.2) izlemektedir. Öğretmenlerin \% 53.3'ü şuan çalıştığı müdürü ile 2 yıl ve altı, \%24.0'ü 3-4 yıl, \%16.9'u 5-6 yıl, \%5.7'i ise 7 yıl üzeri birlikte çalışmakta olduğu görülmektedir.

\section{Veri Toplama Araçları}

Araştırma verilerinin toplanmasında Kişisel Bilgiler Formu, Paternalist Liderlik Ölçeği (PLÖ) ve Okul Kültürü Ölçeği (OKÖ) olmak üzere toplam üç bölümden oluşan bir ölçek kullanılmıştır.

Paternalist Liderlik Ölçeği: Araştırmada veriler, Dağlı ve Ağalday (2017) tarafından geliştirilen “Okul Müdürlerinin Paternalist Liderlik Davranışları Ölçeği” kullanılarak elde edilmiştir. Okul müdürlerinin paternalist liderlik davranışları ile ilgili 22 madde ve dört alt boyut (yardımsever liderlik, ahlaki liderlik, çıarcı liderlik, otoriter liderlik) bulunmaktadır. Ölçekte "10, 12, 15 ve 16" nolu maddeler ters kodlanmıştır. Her alt boyut için açıklanan varyans, birinci faktörde \% 38,56; ikinci faktörde \% 4,80; üçüncü faktörde \% 6,73 ve dördüncü faktörde ise \% 9,84 olduğu belirlenmiş olup dört faktörün de açıkladığı toplam varyans \% 59,93 olarak belirlenmiştir. Doğrulayıcı faktör analizi sonucunda ise ölçeğin yeterli düzeyde uyum indeks değerlerine sahip olduğu görülmüştür. 
Okul Kültürü Ölçeği: Araştırmada Terzi'nin (2005) geliştirmiş olduğu 29 maddelik “Okul Kültürü Ölçeği" kullanılmıştır. Ölçek 29 maddeden ve 4 alt boyuttan (destek, bürokratik, başarı, görev) oluşmaktadır. Güvenirlik için iç tutarlık katsayıları (Cronbach Alpha) hesaplanmıştır. Okul Kültürü Ölçeğini oluşturan dört alt boyutun açıkladığı toplam varyans \% 50.965'dir. Okul Kültürü Ölçeği'nde yer alan faktörlerden birinci faktör Destek Kültürü, ikinci faktör Başarı Kültürü, üçüncü faktör Bürokratik Kültür, dördüncü faktör Görev Kültürü boyutlarını ifade etmektedir. Beşli Likert tipi bir derecelendirme yapılmıştır.

\section{Verilerin Toplanması}

Çalışma verilerinin toplanması için gerekli izinler alınmış olup “Paternalist Liderlik Ölçeği”" ve “Okul Kültürü Ölçeği” 2018-2019 eğitim öğretim yılı içerisinde öğretmenlere uygulanmıştır. Ölçekler uygulanırken gönüllülük esası dikkate alınmış ve gizlilik ilkesi doğrultusunda kişisel bilgilerin kimseye verilmeyeceği açıklanarak öğretmenlerin güveni sağlanmaya çalışılmıştır.

\section{Verilerin Analizi}

Çalışma kapsamında toplanan veriler SPSS programı ile analiz edilmiştir. SPSS paket programı yardımıyla Paternalist Liderlik Ölçeği ve Okul Kültürü Ölçeğinden alınan puanların tanımlanması için ortalama ve standart sapma değerleri hesaplanmış her iki ölçeğin alt boyutları arasındaki ilişki ve değişkenler arasındaki anlamlı farklılıkların hangi tür analizlerle yapılacağına yönelik karar vermek amacıyla dağılımların normalliğinin denetlenmesi için Basıklık (Skewness) ve Çarpıklık (Kurtosis) testleri yapılmıştır (Tablo-2).

\begin{tabular}{|c|c|c|c|c|c|c|c|}
\hline \multirow{2}{*}{ Puanlar } & \multirow{2}{*}{$N$} & \multirow{2}{*}{$\bar{x}$} & \multirow{2}{*}{$S S$} & \multicolumn{2}{|c|}{ Skewness } & \multicolumn{2}{|c|}{ Kurtosis } \\
\hline & & & & Değer & Std & Değer & Std \\
\hline Paternalist Liderlik & 420 & 2,85 & 0,32 & ,235 & ,119 &,- 336 & ,238 \\
\hline Destek Kültürü & 420 & 3,83 & 0,88 &,- 708 & 119 &,- 067 & 238 \\
\hline Başarı Kültürü & 420 & 3,86 & 0,87 &,- 718 & ,119 & ,043 & 238 \\
\hline Bürokrasi Kültürü & 420 & 3,17 & 0,69 &,- 029 & ,119 & ,129 & 238 \\
\hline Görev Kültürü & 420 & 4,17 & 0,67 &,- 751 & ,119 &,- 177 & ,238 \\
\hline
\end{tabular}

Tablo 2' de öğretmenlerin paternalist liderlik ve okul kültürü alt boyutlarına ait puanların normal dağılım gösterip göstermediğine yönelik yapılan normallik testi sonucuna göre basıklık (Skewness) ve çarpıklık (Kurtosis) değerlerinin -/+1 içinde olduğu görülmektedir. Basıklık ve çarpıklık değerleri -/+1 içinde kaldığında, dağılımın normal olduğu kabul edilir (Çokluk, Şekercioğlu ve Büyüköztürk, 2012: 16). Ölçeklerin toplam ve alt boyutlarının puanları basıklık (Skewness) ve çarpıklık (Kurtosis) değerleri -/+1 içinde olduğundan verilerimiz normal dağılım göstermektedir.

İkili grupların karşılaştırılmasında bağımsız gruplar t-testi, ikiden fazla grupların karşılaştırılmasında tek yönlü varyans analizi (ANOVA), paternalist liderlik davranışları ile okul kültürü arasındaki ilişkinin belirlenmesinde korelasyon analizi, paternalist liderlik davranışlarının okul kültürünü yordayıp yordamadığını belirlemek için ise Basit Regresyon Testi kullanılmıştır. 


\section{BULGULAR}

Okul müdürlerinin paternalist liderlik davranışları ve okul kültürüne yönelik öğretmen algılarının ortalamalarını görmek amacıyla yapılan test sonuçları Tablo 3'de verilmiştir.

Tablo 3. Paternalist Liderlik ve Okul Kültürü Aritmetik Ortalama ve Standart Sapma Değerleri

\begin{tabular}{llll}
\multicolumn{1}{c}{ Puanlar } & $\boldsymbol{N}$ & $\overline{\boldsymbol{x}}$ & $\boldsymbol{S S}$ \\
\hline Paternalist Liderlik & 420 & 2,85 & 0,32 \\
\hline Destek Kültürü & 420 & 3,83 & 0,88 \\
\hline Başarı Kültürü & 420 & 3,86 & 0,87 \\
\hline Bürokrasi Kültürü & 420 & 3,17 & 0,69 \\
\hline Görev Kültürü & 420 & 4,17 & 0,67 \\
\hline
\end{tabular}

Tablo 3'de paternalist liderlik davranışları ve okul kültürlerine ilişkin aritmetik ortalamalar ve standart sapmalar verilmiştir. Genel olarak paternalist liderlik davranışları "orta" düzeydedir $(\overline{\boldsymbol{x}}=2,85 ; \mathrm{ss}=, 32)$. Okul kültürü ise sırasiyla destek kültürü "yüksek" düzeyde $(\overline{\boldsymbol{x}}=3,83$; ss=,88); başarı kültürü "yüksek" düzeyde $(\overline{\boldsymbol{x}}=3,86$; ss=,87); bürokrasi kültürü "orta" düzeyde $(\overline{\boldsymbol{x}}=3,17$; ss $=, 69)$ ve görev kültürü "yüksek" düzeyde $(\overline{\boldsymbol{x}}=4,17$; ss=,67) olduğu belirlenmiştir.

Okul müdürlerinin paternalist liderlik ve okul kültürü davranışlarının öğretmenlerin cinsiyetlerine göre anlamlı farklılık gösterip-göstermediğini belirlemek amacıyla yapılan $t$ testi sonuçları Tablo 4'te verilmiştir.

Tablo 4. Öğretmenlerin Paternalist Liderlik ve Okul Kültürü Algılarının Cinsiyetlerine Göre Farklılaşıp-Farklılaşmadığını Gösterir t- Testi Analiz Sonucu

\begin{tabular}{|c|c|c|c|c|c|c|c|}
\hline \multirow{2}{*}{ Alt Boyutları } & \multirow{2}{*}{ Gruplar } & \multirow{2}{*}{$N$} & \multirow{2}{*}{$\bar{x}$} & \multirow{2}{*}{$S S$} & \multicolumn{3}{|c|}{$t-$ Testi } \\
\hline & & & & & $t$ & $S d$ & $p$ \\
\hline \multirow{2}{*}{ Paternalist Liderlik } & Erkek & 139 & 2,93 & ,318 & \multirow{2}{*}{3,808} & \multirow{2}{*}{418} & \multirow{2}{*}{,000 } \\
\hline & Kadın & 281 & 2,81 & ,325 & & & \\
\hline \multirow{2}{*}{ Destek Kültürü } & Erkek & 139 & 3,91 & 84 & \multirow{2}{*}{1,29} & \multirow{2}{*}{418} & \multirow{2}{*}{ 195 } \\
\hline & Kadın & 281 & 3,79 &, 90 & & & \\
\hline \multirow{2}{*}{ Başarı Kültürü } & Erkek & 139 & 3,98 & 86 & \multirow{2}{*}{1,94} & \multirow{2}{*}{418} & \multirow{2}{*}{,052 } \\
\hline & Kadın & 281 & 3,80 & 87 & & & \\
\hline \multirow{2}{*}{ Bürokrasi Kültürü } & Erkek & 139 & 3,19 & 65 & \multirow{2}{*}{ 400 } & \multirow{2}{*}{418} & \multirow{2}{*}{ 690 } \\
\hline & Kadin & 281 & 3,16 & ,71 & & & \\
\hline \multirow{2}{*}{ Görev Kültürü } & Erkek & 139 & 4,26 & 63 & \multirow{2}{*}{1,97} & \multirow{2}{*}{418} & \multirow{2}{*}{,049 } \\
\hline & Kadın & 281 & 4,13 & 68 & & & \\
\hline
\end{tabular}

Tablo 4'deki bulgular incelendiğinde öğretmenlerin paternatlist liderlik davranışları ( $\mathrm{t}=3,808$; $\mathrm{p}<.05)$ ve görev kültürü algıları ( $\mathrm{t}=1,97 ; \mathrm{p}<.05)$ cinsiyetlerine göre anlamlı bir farklılık oluşturduğu görülmüştür. Erkek öğretmenler $(\overline{\boldsymbol{x}}=2.93)$ okul müdürlerini kadın öğretmenlere $(\overline{\boldsymbol{x}}=2.81)$ göre daha fazla paternalist lider olarak algılamaktadır. Ayrıca erkek öğretmenlerin $(\overline{\boldsymbol{x}}=4.26)$ görev kültürü algıları kadın öğretmenlere $(\overline{\boldsymbol{x}}=4.13)$ göre daha yüksektir.

Okul müdürlerinin öğretmenler tarafından algılanan paternalist liderlik davranışları ve okul kültürü algılarının öğretmenlerin eğitim düzeylerine göre anlamlı farklılık gösteripgöstermediğini belirlemek amacıyla yapılan t-testi sonuçları Tablo $5^{\prime}$ te verilmiştir. 
Tablo 5. Öğretmenlerin Paternalist Liderlik ve Okul Kültürü Algılarının Eğitim Durumlarına Göre Farklılaşıp-Farklılaşmadığını Gösterir t- Testi Analiz Sonucu

\begin{tabular}{|c|c|c|c|c|c|c|c|}
\hline \multirow{2}{*}{ Alt Boyutları } & \multirow{2}{*}{ Gruplar } & \multirow{2}{*}{$N$} & \multirow{2}{*}{$\bar{x}$} & \multirow{2}{*}{ SS } & \multicolumn{3}{|c|}{$t$-Testi } \\
\hline & & & & & $t$ & $S d$ & $p$ \\
\hline \multirow{2}{*}{ Paternalist Liderlik } & Lisans & 350 & 2,83 & ,325 & \multirow{2}{*}{$-1,830$} & \multirow{2}{*}{418} & \multirow{2}{*}{,068 } \\
\hline & Y. Lisans & 70 & 2,91 & ,337 & & & \\
\hline \multirow{2}{*}{ Destek Kültürü } & Lisans & 350 & 3,87 & 85 & \multirow{2}{*}{2,40} & \multirow{2}{*}{418} & \multirow{2}{*}{,017 } \\
\hline & Y. Lisans & 70 & 3,60 & 1,00 & & & \\
\hline \multirow{2}{*}{ Başarı Kültürü } & Lisans & 350 & 3,90 & 85 & \multirow{2}{*}{2,14} & \multirow{2}{*}{418} & \multirow{2}{*}{,032 } \\
\hline & Y. Lisans & 70 & 3,66 & ,97 & & & \\
\hline \multirow{2}{*}{ Bürokrasi Kültür } & Lisans & 350 & 3,17 & ,67 & \multirow{2}{*}{,- 194} & \multirow{2}{*}{418} & \multirow{2}{*}{846} \\
\hline & Y. Lisans & 70 & 3,19 & ,79 & & & \\
\hline \multirow{2}{*}{ Görev Kültürü } & Lisans & 350 & 4,19 & ,66 & \multirow{2}{*}{1,10} & \multirow{2}{*}{418} & \multirow{2}{*}{ 268 } \\
\hline & Y. Lisans & 70 & 4,09 & ,68 & & & \\
\hline
\end{tabular}

Tablo 5'te bulgular incelendiğinde öğretmenlerin algıladıkları paternalist liderlik ve okul kültürü ölçeği puanlarında eğitim düzeylerine göre anlamlı bir farklılık olup olmadığını tespit etmek için yapılan $\mathrm{t}$-testi sonucunda destek kültürü $(\mathrm{t}=2,40 ; \mathrm{p}<.05)$ ve başarı kültürü $(\mathrm{t}=2,14 ; \mathrm{p}<.05)$ puan ortalamalarının anlamlı bir fark oluşturduğu görülmüştür. Lisans mezunu öğretmenler, yüksek lisans mezunu öğretmenlere göre okullarında destek ve başarı kültürünün daha baskın olduğunu düşünmektedir.

Okul müdürlerinin paternalist liderlik ve okul kültürü davranışlarının öğretmenlerin yaş düzeylerine göre anlamlı farklılık gösterip göstermediğini belirlemek amacıyla yapılan tek yönlü varyans (ANOVA) analizi sonuçları Tablo 6'da verilmiştir.

Tablo $6^{\prime}$ da görüldüğü üzere okul müdürlerinin öğretmenlerin algıladıkları paternalist liderlik davranışları yaşlarına göre anlamlı farklılık bulunmazken; başarı ve görev kültüründe anlamlı fark bulunmuştur $(\mathrm{p}<, 05)$. Farklılığın hangi gruplar arasında bulunduğunu tespit etmek amacıyla yapılan post hoc testlerinden LSD testi sonucuna göre; 51 yaş ve üstü öğretmenlerin başarı kültürü algıları $(\overline{\boldsymbol{x}}=4,28), 31-40$ yaş $(\overline{\boldsymbol{x}}=3,77)$ ve $41-50$ yaş $(\overline{\boldsymbol{x}}=3,83)$ öğretmenlerden daha yüksektir. Ayrıca 51 yaş üstü öğretmenlerin görev kültürü algıları $(\overline{\boldsymbol{x}}=4,54), 31-40$ yaş $(\overline{\boldsymbol{x}}=4,11), 30$ yaş altı $(\overline{\boldsymbol{x}}=4,17)$ ve $41-50$ yaş $(\overline{\boldsymbol{x}}=4,18)$ öğretmenlerden daha yüksektir.

Okul müdürlerinin paternalist liderlik ve okul kültürü davranışlarının öğretmenlerin okul türüne göre anlamlı farklılık gösterip göstermediğini belirlemek amacıyla yapılan tek yönlü varyans (ANOVA) analizi sonuçları Tablo 7'de verilmiştir.

Tablo 7'de öğretmenlerin algıladıkları paternalist liderlik davranışları görev yaptıkları anaokulu, ilkokul, ortaokul ve lise kademelerine göre anlamlı bir farklılık bulunmazken ( $>$ >05); okul kültürü açısından anlamlı fark bulunmaktadır $(\mathrm{p}<.05)$. Farklılığın hangi gruplar arasında bulunduğunu tespit etmek amaciyla yapılan post hoc testlerinden LSD testi sonucuna göre; anaokulu $(\overline{\boldsymbol{x}}=4,33)$ ve ilkokul öğretmenlerinin destek kültürü algıları $(\overline{\boldsymbol{x}}=4,08)$, ortaokul $(\overline{\boldsymbol{x}}=3,80)$ ve lise öğretmenlerinden $(\overline{\boldsymbol{x}}=3,57)$; ortaokul öğretmenlerinin destek kültürü algıları $(\overline{\boldsymbol{x}}=3,80)$, lise öğretmenlerinden $(\overline{\boldsymbol{x}}=3,57)$ daha yüksektir. 
Tablo 6. Öğretmenlerin Paternalist Liderlik ve Okul Kültürü Algılarının Yaşlarına Göre Farklılaşıp-Farklılaşmadığını Gösterir ANOVA Analizi Sonuçları

\begin{tabular}{|c|c|c|c|c|c|c|c|c|c|c|c|}
\hline Puan & Sinif & $\mathbf{N}$ & $\bar{x}$ & Ss & $\begin{array}{l}\text { Varyansın } \\
\text { Kaynağı }\end{array}$ & KT & sd & KO & $\mathbf{F}$ & p & Fark \\
\hline \multirow{5}{*}{ 声 } & A-30 yaş altı & 131 & 3.87 & .86 & G. Arası & 5,46 & 3 & 1,823 & \multirow{5}{*}{2,34} & \multirow{5}{*}{,072 } & \multirow{5}{*}{--- } \\
\hline & B-31-40 yaş & 179 & 3.72 & .93 & G. İçi & 323,3 & 416 & 777 & & & \\
\hline & C-41-50 yaş & 84 & 3.87 & .88 & Toplam & 328,8 & 419 & & & & \\
\hline & $\begin{array}{l}\text { D-51 yaş ve } \\
\text { üstü }\end{array}$ & 26 & 4,17 & .56 & & & & & & & \\
\hline & Toplam & 420 & 3.83 & .88 & & & & & & & \\
\hline \multirow{5}{*}{ 包 } & A-30 yaş altı & 131 & 3.92 & .78 & G. Arası & 6,53 & 3 & 2,179 & \multirow{5}{*}{2,87} & \multirow{5}{*}{,036 } & \multirow{5}{*}{$\begin{array}{l}\mathrm{D}>\mathrm{B} ; \\
\mathrm{D}>\mathrm{C}\end{array}$} \\
\hline & B-31-40 yaş & 179 & 3.77 & .91 & G. İçi & 315,4 & 416 & 758 & & & \\
\hline & C-41-50 yaş & 84 & 3.83 & .96 & Toplam & 322,0 & 419 & & & & \\
\hline & $\begin{array}{l}\text { D-51 yaş ve } \\
\text { üstü }\end{array}$ & 26 & 4,28 & .56 & & & & & & & \\
\hline & Toplam & 420 & 3.86 & .87 & & & & & & & \\
\hline \multirow{5}{*}{ 记 } & A-30 yaş altı & 131 & 3.27 & .65 & G. Aras1 & 1,93 & 3 & 643 & \multirow{5}{*}{1,32} & \multirow{5}{*}{,267 } & \multirow{5}{*}{--- } \\
\hline & B-31-40 yaş & 179 & 3.12 & .75 & G. İçi & 202,5 & 416 & ,487 & & & \\
\hline & C-41-50 yaş & 84 & 3.11 & .65 & Toplam & 204,5 & 419 & & & & \\
\hline & $\begin{array}{l}\text { D-51 yaş ve } \\
\text { üstü }\end{array}$ & 26 & 3.23 & .63 & & & & & & & \\
\hline & Toplam & 420 & 3.17 & .69 & & & & & & & \\
\hline \multirow{5}{*}{ 总: } & A-30 yaş altı & 131 & 4.17 & .64 & G. Aras1 & 4,16 & 3 & 1,381 & \multirow{5}{*}{3,11} & \multirow{5}{*}{,026 } & \multirow{5}{*}{$\begin{array}{l}\mathrm{D}>\mathrm{A} ; \\
\mathrm{D}>\mathrm{B} ; \\
\mathrm{D}>\mathrm{C}\end{array}$} \\
\hline & B-31-40 yaş & 179 & 4.11 & .69 & G. İçi & 185,5 & 416 & ,446 & & & \\
\hline & C-41-50 yaş & 84 & 4.18 & .68 & Toplam & 189,7 & 419 & & & & \\
\hline & $\begin{array}{l}\text { D-51 yaş ve } \\
\text { üstü }\end{array}$ & 26 & 4.54 & .50 & & & & & & & \\
\hline & Toplam & 420 & 4.17 & .67 & & & & & & & \\
\hline \multirow{5}{*}{ 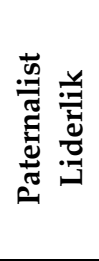 } & A-30 yaş altı & 131 & 2,80 & ,02 & G. Aras1 & ,508 & 3 & 169 & \multirow{5}{*}{1,57} & \multirow{5}{*}{, 194 } & \multirow{5}{*}{---} \\
\hline & B-31-40 yaş & 179 & 2,85 & ,02 & G. İçi & 44,66 & 416 & , 107 & & & \\
\hline & C-41-50 yaş & 84 & 2,88 & ,03 & Toplam & 45,17 & 419 & & & & \\
\hline & $\begin{array}{l}\text { D-51 yaş ve } \\
\text { üstü }\end{array}$ & 26 & 2,93 & ,05 & & & & & & & \\
\hline & Toplam & 420 & 2,85 & ,01 & & & & & & & \\
\hline
\end{tabular}


Tablo 7. Öğretmenlerin Paternalist Liderlik ve Okul Kültürü Algılarının Okul Kademelerine Göre Farklılaşıp-Farklılaşmadığını Gösterir ANOVA Analizi Sonuçları

\begin{tabular}{|c|c|c|c|c|c|c|c|c|c|c|c|}
\hline Puan & Sinif & $\mathbf{N}$ & $\bar{x}$ & Ss & $\begin{array}{l}\text { Varyansın } \\
\text { Kaynağı }\end{array}$ & KT & sd & KO & $\mathbf{F}$ & p & Fark \\
\hline \multirow{5}{*}{ 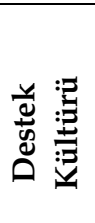 } & A-Anaokulu & 26 & 4.33 & .65 & G. Arası & 20,74 & 3 & 6,916 & \multirow{5}{*}{9,33} & \multirow{5}{*}{,000 } & $A>C$ \\
\hline & B-İlkokul & 93 & 4.08 & .84 & G. İçi & 308,0 & 416 & 741 & & & $\mathrm{A}>\mathrm{D}$ \\
\hline & C-Ortaokul & 176 & 3.80 & .82 & Toplam & 328,8 & 419 & & & & $\mathrm{~B}>\mathrm{C}$; \\
\hline & D-Lise & 125 & 3.57 & .95 & & & & & & & $\mathrm{~B}>\mathrm{D}$; \\
\hline & Toplam & 420 & 3.83 & .88 & & & & & & & $\mathrm{C}>\mathrm{D}$ \\
\hline \multirow{5}{*}{ 疍 } & A-Anaokulu & 26 & 4.35 & .54 & G. Arası & 15,2 & 3 & 5,069 & \multirow{5}{*}{6,87} & \multirow{5}{*}{, 000} & \multirow{5}{*}{$\begin{array}{l}\mathrm{A}>\mathrm{C} ; \\
\mathrm{A}>\mathrm{D} ; \\
\mathrm{B}>\mathrm{C} ; \\
\mathrm{B}>\mathrm{D}\end{array}$} \\
\hline & B-İlkokul & 93 & 4.06 & .90 & G. İçi & 306,8 & 416 & ,738 & & & \\
\hline & C-Ortaokul & 176 & 3.83 & .82 & Toplam & 322,0 & 419 & & & & \\
\hline & D-Lise & 125 & 3.66 & .91 & & & & & & & \\
\hline & Toplam & 420 & 3.86 & .87 & & & & & & & \\
\hline \multirow{5}{*}{ 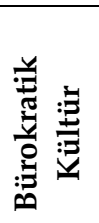 } & A-Anaokulu & 26 & 2.89 & .61 & G. Arası & 3,82 & 3 & 1,276 & \multirow{5}{*}{2,64} & \multirow{5}{*}{,049 } & \multirow{5}{*}{$\mathrm{D}>\mathrm{A}$} \\
\hline & B-İlkokul & 93 & 3.13 & .76 & G. İçi & 200,7 & 416 & ,483 & & & \\
\hline & C-Ortaokul & 176 & 3.16 & .65 & Toplam & 204,5 & 419 & & & & \\
\hline & D-Lise & 125 & 3.28 & .71 & & & & & & & \\
\hline & Toplam & 420 & 3.17 & .69 & & & & & & & \\
\hline \multirow{5}{*}{ 党 } & A-Anaokulu & 26 & 4.36 & .51 & G. Arası & 7,86 & 3 & 2,62 & \multirow{5}{*}{5,99} & \multirow{5}{*}{,001 } & \multirow{5}{*}{$\begin{array}{l}\mathrm{A}>\mathrm{D} ; \\
\mathrm{B}>\mathrm{C} ; \\
\mathrm{B}>\mathrm{D} ; \\
\mathrm{C}>\mathrm{D}\end{array}$} \\
\hline & B-İlkokul & 93 & 4.36 & .64 & G. İçi & 181,2 & 416 & 437 & & & \\
\hline & C-Ortaokul & 176 & 4.16 & .69 & Toplam & 189,7 & 419 & & & & \\
\hline & D-Lise & 125 & 4.00 & .64 & & & & & & & \\
\hline & Toplam & 420 & 4.17 & .67 & & & & & & & \\
\hline \multirow{5}{*}{ 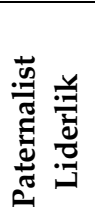 } & A-Anaokulu & 26 & 2.86 & ,30 & G. Arası & 269 & 3 & ,090 & \multirow{5}{*}{,831 } & \multirow{5}{*}{477} & \multirow{5}{*}{---} \\
\hline & B-İlkokul & 93 & 2.83 & ,30 & G. İçi & 44,90 & 416 & 108 & & & \\
\hline & C-Ortaokul & 176 & 2.83 & ,32 & Toplam & 45,17 & 419 & & & & \\
\hline & D-Lise & 125 & 2.89 & ,35 & & & & & & & \\
\hline & Toplam & 420 & 2.85 & ,32 & & & & & & & \\
\hline
\end{tabular}

Anaokulu $(\overline{\boldsymbol{x}}=4,35)$ ve ilkokul $(\overline{\boldsymbol{x}}=4,06)$ öğretmenlerinin başarı kültürü algıları $(\overline{\boldsymbol{x}}=4,06)$, ortaokul $(\overline{\boldsymbol{x}}=3,83)$ ve lise öğretmenlerinin başarı kültürü algılarından $(\overline{\boldsymbol{x}}=3,66)$ daha yüksektir.

Lise öğretmenlerinin bürokratik kültür algıları $(\overline{\boldsymbol{x}}=3,28)$, anaokulu öğretmenlerinin bürokratik kültür algılarından $(\overline{\boldsymbol{x}}=2,89)$ daha yüksektir.

Anaokulu $(\overline{\boldsymbol{x}}=4,36)$, ilkokul $(\overline{\boldsymbol{x}}=4,36)$ ve ortaokul $(\overline{\boldsymbol{x}}=4,16)$, öğretmenlerinin görev kültürü algıları, lise öğretmenlerinin görev kültürü algılarından $(\bar{x}=4,00)$ daha yüksektir.

Okul müdürlerinin paternalist liderlik davranışlarının ve okul kültürü algıları öğretmenlerin şuanki müdürle çalışma yılına göre anlamlı farklılık gösterip göstermediğini belirlemek amacıyla yapılan tek yönlü varyans (ANOVA) analizi sonuçları Tablo 8' de verilmiştir. 
Tablo 8. Öğretmenlerin Paternalist Liderlik ve Okul Kültürü Algılarının Şu anki Müdürle Çalışma Yıllarına Göre Farklılaşıp-Farklılaşmadığını Gösterir ANOVA Analizi Sonuçları

\begin{tabular}{|c|c|c|c|c|c|c|c|c|c|c|c|}
\hline Puan & Sinıf & $\mathbf{N}$ & $\bar{x}$ & Ss & $\begin{array}{c}\text { Varyansın } \\
\text { Kaynağı }\end{array}$ & KT & sd & KO & $\mathbf{F}$ & p & Fark \\
\hline \multirow{5}{*}{ 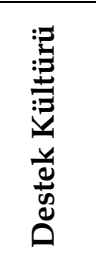 } & 2 yıl ve altı & 224 & 3.78 & .88 & G. Arası & 2,21 & 3 & 737 & \multirow{5}{*}{,939 } & \multirow{5}{*}{,422 } & \multirow{5}{*}{--- } \\
\hline & 3-4 yıl & 101 & 3.85 & .92 & G. İçi & 326,59 & 416 & 785 & & & \\
\hline & $5-6$ yil & 71 & 3.86 & .84 & Toplam & 328,80 & 419 & & & & \\
\hline & $\begin{array}{l}7 \text { yıl ve } \\
\text { üstü }\end{array}$ & 24 & 4,07 & .82 & & & & & & & \\
\hline & Toplam & 420 & 3.83 & .88 & & & & & & & \\
\hline \multirow{5}{*}{ 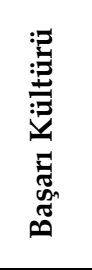 } & 2 y1l ve altı & 224 & 3.82 & .85 & G. Aras1 & 1,11 & 3 & 370 & \multirow{5}{*}{, 480} & \multirow{5}{*}{ 696 } & \multirow{5}{*}{--- } \\
\hline & 3-4 y1l & 101 & 3.88 & .93 & G. İçi & 320,90 & 416 & 771 & & & \\
\hline & $5-6$ yil & 71 & 3.91 & .89 & Toplam & 322,01 & 419 & & & & \\
\hline & $\begin{array}{l}7 \text { yıl ve } \\
\text { üstü }\end{array}$ & 24 & 4,01 & .85 & & & & & & & \\
\hline & Toplam & 420 & 3.86 & .87 & & & & & & & \\
\hline \multirow{5}{*}{ 范 } & 2 yıl ve altı & 224 & 3.17 & .72 & G. Arası & 1,15 & 3 & ,517 & \multirow{5}{*}{1,059} & \multirow{5}{*}{,367 } & \multirow{5}{*}{---} \\
\hline & 3-4 y1l & 101 & 3.25 & .66 & G. İçi & 203,00 & 416 & ,488 & & & \\
\hline & $5-6$ y1l & 71 & 3.14 & .64 & Toplam & 204,55 & 419 & & & & \\
\hline & $\begin{array}{l}7 \text { yıl ve } \\
\text { üstü }\end{array}$ & 24 & 2.98 & .72 & & & & & & & \\
\hline & Toplam & 420 & 3.86 & .69 & & & & & & & \\
\hline \multirow{5}{*}{ 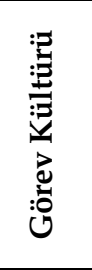 } & 2 yıl ve altı & 224 & 4.13 & .65 & G. Arası & 1,30 & 3 & ,435 & \multirow{5}{*}{,960 } & \multirow{5}{*}{,412 } & \multirow{5}{*}{--- } \\
\hline & 3-4 y1l & 101 & 4.19 & .73 & G. İçi & 188,40 & 416 & ,453 & & & \\
\hline & 5-6 y1l & 71 & 4.27 & .61 & Toplam & 189,70 & 419 & & & & \\
\hline & $\begin{array}{l}7 \text { y1l ve } \\
\text { üstü }\end{array}$ & 24 & 4.24 & .70 & & & & & & & \\
\hline & Toplam & 420 & 4.17 & .67 & & & & & & & \\
\hline \multirow{5}{*}{ 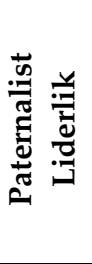 } & 2 yıl ve altı & 224 & 2.83 & .32 & G. Arası & 291 & 3 & ,097 & \multirow{5}{*}{,900 } & \multirow{5}{*}{,441 } & \multirow{5}{*}{--- } \\
\hline & 3-4 y1l & 101 & 2.86 & .34 & G. İçi & 44,88 & 416 & 108 & & & \\
\hline & 5-6 y1l & 71 & 2.87 & .30 & Toplam & 45,17 & 419 & & & & \\
\hline & $\begin{array}{l}7 \text { yıl ve } \\
\text { üstü }\end{array}$ & 24 & 2.92 & .31 & & & & & & & \\
\hline & Toplam & 420 & 2.85 & .32 & & & & & & & \\
\hline
\end{tabular}

Tablo 8'e göre, öğretmenlerin şu anki müdürle çalışma yılları, paternalist liderlik ve okul kültürü ölçeğinden aldıkları puan ortalamaları açısından anlamlı farklılık bulunmamaktadır ( $p>.05)$.

Okul müdürlerinin paternalist liderlik davranışları ve okul kültürü arasındaki ilişkinin belirlenmesine yönelik yapılan korelasyon analizi sonuçları Tablo 9'da verilmiştir.

Tablo 9'da görüldüğü üzere okul müdürlerinin öğretmenler tarafından algılanan paternalist liderlik davranışları ile okul kültürü arasında anlamlı bir ilişki olup olmadığına yönelik yapılan Pearson Korelasyon analizi sonucunda, bürokratik kültür ile paternalist liderlik davranışları arasında pozitif yönde anlamlı bir ilişki olduğu tespit edilmiştir $(r=, 235 ; p<, 01)$. Paternalist liderlik davranışları ile destek, başarı ve görev kültürleri arasında anlamlı bir ilişki bulunamamıştır $(p<.05)$. 
Tablo 9. Paternalist Liderlik Davranışları ile Okul Kültürü Arasındaki İlişkiler için Yapılan Pearson Analizi Sonuçları

\begin{tabular}{lccc}
\hline \multirow{2}{*}{ Okul Kültürü Alt Boyutları } & \multicolumn{3}{c}{ Paternalist Liderlik Toplam Puanı } \\
\cline { 2 - 4 } & $\mathbf{N}$ & $\mathbf{~ r}$ & $\mathbf{p}$ \\
\hline Destek Külttürü & 420 &,- 092 &, 060 \\
Başarı Kültürü & 420 &,- 061 &, 210 \\
Bürokrasi Kültürü & 420 &, $235^{* *}$ &, 000 \\
Görev Kültürü & 420 &,- 016 &, 751 \\
\hline
\end{tabular}

Paternalist liderlik davranışlarının, bürokratik okul kültürünü yordayıp yordamadığını ortaya koymak için yapılan basit regresyon analizi Tablo 10'da yer almaktadır.

\begin{tabular}{lcccccc}
\hline \multicolumn{7}{l}{ Tablo 10. Regresyon Analizi Kapsamindaki Varyans Analizi } \\
\hline B.S1z Değ. & B.1ı Değ. & B & Std. Hata & $\boldsymbol{\beta}$ & $\mathbf{t}$ & $\mathbf{p}$ \\
\hline Sabit & Bürokrasi & 1,749 &, 290 & & 6,019 &, 000 \\
PaternalistL. & Kültürü &, 501 &, 101 &, 235 & 4,951 &, 000 \\
\hline $\mathrm{R}=.235 ; \mathrm{R}^{2}=.055 ; \mathrm{F}=24.51 ; \mathrm{p}<.05$ & & & & & \\
\hline
\end{tabular}

Tablo 10'da görüldüğü üzere, regresyon analizi modelinde paternalist liderlik davranışları bağımsız, bürokratik okul kültürü bağımlı değişken olarak tanımlanmıştır. Okul müdürlerinin öğretmenler tarafından algılanan paternalist liderlik davranışları, bürokratik okul kültürünü anlamlı bir şekilde yordamaktadır. Okul müdürlerinin paternalist liderlik davranışları, bürokratik okul kültüründeki toplam varyansın yaklaşık \%6'sını açıklamaktadır. Başka bir ifadeyle okul müdürlerinin paternalist liderlik davranışları, bürokratik okul kültürünü olumlu yönde etkilemektedir.

\section{TARTIŞMA, SONUÇ VE ÖNERİLER}

Araştırmanın birinci alt amacına ait bulgular incelendiğinde, "öğretmenlerin okul müdürlerinin paternalist liderlik davranışlarına" ilişkin algılarının "orta" düzeyde olduğu sonucuna ulaşılmıştır. Bu sonucun literatürdeki diğer sonuçlarla paralellik göstermektedir (Cerit ,2012; Arslan, 2016; Sarp, Kumral ve Bozkurt, 2019). Ülkemizde yapılan araştırmalarda paternalist liderlik davranışlarının düşük algılanması, daha ziyade doğu toplumlarında görülen aile ortamı, sadakat, yardımseverlik, otoriterlik, disiplin gibi unsurların değişen yüzyılda etkililiğini yitirmesi ve batı tarzı liderlik türlerinden daha çok etkilendiği gözlemlenen Türkiye coğrafyası için beklenen bir sonuç olduğu düşünülmektedir.

Araştırmada elde edilen diğer bulgulara göre okullarda görev odaklı bir okul kültürünün oluştuğundan bahsedilebilir. Öğretmen algılarına göre araştırmanın sonuçları, okullarda görev kültürünün daha baskın olduğunu ortaya koymuş ve yapılan bazı araştırma bulgularıyla paralel olduğu görülmüştür (Esinbay, 2008; Koşar, 2008; Terzi, 2005; Sezgin, 2010; Koşar ve Çalık, 2011; Özdemir, 2013). Her şeyin belirli bir amaca yönelik olması beklenen görev kültüründe iş merkezli bir anlayış hakimdir (Şişman, 2002). Bu araştırmada öğretmenlerin görev kültürüne ilişkin algılarının daha yüksek çıkması, öğretmenlerin sorumluluk gerektirdiği davranışları yapmaya 
çalıştıkları şeklinde yorumlanabilirken, devlet okullarında öğretmenlere yüklenen görev bilinci algısının da bir sonucu olduğu düşünülmektedir. Bürokratik kültür ise en düşük algılana okul kültürü boyutu olmuştur. Dönder'e (2006) göre okulların kuralcı bir tarz ile yönetilmesi, okulun atmosferini olumsuz etkilemekte ve örgütte otoritenin hiyerarşik kullanımı artıkça ilişkiler resmileşmektedir. Resmileşen ilişkiler kurumu (Hersey ve Blanchard, 1982) izleyicilerin gözüne yüzeysel, zayıf ve ilişkilerin resmileştiği yer olarak yansımaktadır. Buna bağlı olarak araştırmada öğretmenlerin okul kültürüne ilişkin algılarının en düşük düzeyde algılandığı bürokratik kültür boyutunun yer alması olumlu bir sonuç olarak görülmektedir.

Araştırmanın cevap aradığı ikinci alt amaçta ise öğretmenlerin demografik özelliklerin öğretmenlerin paternalist liderlik algıları üzerinde farklılık oluşturup oluşturmadığıdır. Öğretmenlerin eğitim düzeyi paternalist liderlik davranışları algılarında anlamlı farklılık oluşturmazken; erkek öğretmenler okul müdürlerini kadın öğretmenlere göre daha fazla babacan lider olarak algılamaktadır. Dağlı ve Ağalday (2017), Cesur (2015) ve Yaman'ın (2011) araştırmalarında elde edilen bulgular, mevcut araştırmadan elde edilen bulgular ile benzerlik göstermektedir. Erkek öğretmenler, paternalist liderden iş yerinde daha fazla aile ortamı yaratmasını ve aynı şekilde daha fazla kişisel hayatlarına katılmasını beklemektedir. Dolayısıyla lider ile izleyici arasındaki ilişkinin erkek katılımcılarda daha fazla ebeveyn - evlat ilişkisine doğru ilerlediğini söyleyebiliriz. Başka bir yorumda okul müdürlerinin çoğunun erkek egemen olması kadın öğretmenler ile empati yapamamalarının yanında Doğu kültüründe toplumsal cinsiyet algısı sebebiyle kadın-erkek ilişkilerinin uzak olmasının etkili olduğu varsayılabilir. Sonuçlara göre yaş, okul türü ve şu an ki müdürle çalışma yılının öğretmenler algısında anlamlı bir farklılığa yol açmadığı belirlenmiştir.

Araştırmada öğretmenlerin cinsiyetlerine göre görev kültürü bakımından erkek öğretmenlerin lehine bir farklılık oluşturduğu görülmektedir. Benzer şekilde erkeklerin destek, başarı ve bürokratik kültür algıları kadınlardan yüksek olduğunu tespit eden çalışmalar bulunmakla birlikte (Tanrı̈ğen, Baştürk ve Başer, 2014; Sönmez, 2006; Özer ve Akbaş, 2016), örgüt kültüründe cinsiyet değişkeninin kültür algısında farklılık oluşturmadığını (Bağdatlı, 2015; Bökeoğlu ve Yılmaz, 2008) ve kadınların örgüt kültürü algılarının erkeklere göre daha yüksek olduğunu tespit eden araştırmalara da (Önsal, 2012; Conn, 2004) rastlamak mümkündür. Araştırmalarda ortaya konulan bulgular değerlendirildiğinde çok farklı sonuçlar çıktığı görülmektedir. Bu sebeple cinsiyet yönünden okul kültürünün algılanması farklı çalışma alanlarında ve örgüt türlerinde değişkenlik gösterebileceği sonucu çıkarımı yapılabilir.

Araştırmada ulaşılan bir başka bulguya göre lisans mezunu öğretmenlerin destek ve başarı kültürü algıları, yüksek lisans mezunu öğretmenlere göre daha olumludur/yüksektir. Farklı araştırma bulguları benzer sonuçlara ulaşırken (Önsal, 2012), bu bulguların aksine eğitim düzeyinin örgüt kültürü algısında anlamlı farklılık oluşmadığını ortaya çıkaran çalışmalar da bulunmaktadır (Bağdatlı, 2015). Bunun sebebi okul çevresi, okulun öğrenci başarısı, öğrenci yaş grupları ve okulların özel veya genel amaçları olabileceği düşünülmektedir.

Araştırmada ulaşılan en dikkat çekici diğer bulguya göre okul müdürlerinin öğretmenler tarafından algıladıkları paternalist liderlik davranışları ile bürokratik okul kültürü arasında pozitif yönde anlamlı bir ilişki tespit edilirken; başarı, görev ve destek kültürleri ile paternalist liderlik davranışları arasında anlamlı bir ilişki tespit edilememiştir. Ayrıca okul müdürlerinin paternalist liderlik davranışları, bürokratik okul kültürünü düşük düzeyde de olsa olumlu yönde yordamaktadır. Başka bir ifadeyle okul müdürlerinin paternalist liderlik davranışları, bürokratik okul kültürünün olumlu yönde gelişmesini desteklemektedir. Okul kültürü ile liderlik arasındaki ilişkiyi belirlemeye yönelik bazı araştırmalar incelendiğinde bu araştırmanın sonuçları ile benzeştiği görülmektedir (Yalınkılıç, 2012; Turan ve Bektaş, 2013; Yalçın ve Karadağ, 2013). Ayrıca Kurşun (2019) tarafından yapılan meta-analiz çalışmasında liderlik ve okul kültürü 
algılarını ilişkilendiren 52 araştırmanın 49'nda pozitif anlamlı ilişki olduğunu tespit etmesi bu araştırma da ulaşılan bulguları güçlendirmektedir. Çeşitli araştırmalarda yöneticilerin paternalist liderlik davranışlarının yöneticiden alınan doyumu (Cerit, 2012), örgütsel iletişimi (Taşlıyan, Çiçeklioğlu ve Bıyıkbeyi, 2017), örgütsel vatandaşlık davranışını (Şendoğdu ve Erdirençelebi, 2014), örgütsel muhalefet ve örgütsel yaratıcılığ1 (Ağalday, 2017), üyelerin psikolojik güçlenmesini (Demirer, 2012), genel iş doyumunu (Nal, 2018), olumlu yönde; işten ayrılma niyetlerini (Özer ve Yurdun, 2012) ise olumsuz yönde etkilediği ortaya konulmuştur. Araştırmamız sonucunda öğretmen algıları, okul müdürleri tarafından sergilenen paternalist liderlik davranışlarının güçlü bir okul kültürü oluşturmada olumlu bir ilişkiye ve etkiye sahip olmadığını da göstermektedir.

Okul kültürüne güçlü katkı sağlaması beklenen okul müdürleri, öğretmenlerin fikirlerine önem veren, onlara rehber olan, etkili işbirliği içerisinde çalışabilmeleri için farklı fırsatlar tanıyan, okul için vizyon ve misyonu oluşturan bir liderdir (Schooley, 2005). Buna bağlı olarak bu araştırmanın okul müdürlerinin göstermesi beklenen liderlik davranışlarının etkili ve sağlıklı bir okul kültürü inşa etmeye sağlayacakları katkının önemini teyit ettiği düşünülmektedir. Okul müdürlerinin hedeflerin kabul görmesine yönelik yüksek performans beklentisi oluşturup birlikte hareket ruhu ile gösterdikleri liderlik davranışları okul kültürünün bir yordayıcısı olmaktadır. Bu sebeple okul müdürlerinin liderlik davranışlarını geliştirmelerinin, kalıcı bir okul kültürü oluşturmada pozitif yönde etkiye sahip olacağını göz önünde bulundurmaları önerilebilir.

\section{KAYNAKÇA}

Akıncı, Z. B. (1998). Kurum Kültürü ve Örgütsel İletişim. İstanbul: İletişim Yayınları.

Arslan, Ö. (2016). Okul Yöneticilerinin Paternalist Liderlik Düzeyleri ile Öğretmenlerin Örgütsel Sinizm Algıları Arasındaki İlişki, Yayınlanmamış Yüksek Lisans Tezi, Uşak Üniversitesi, Uşak.

Aslan, Ş. (2013). Geçmişten Günümüze Liderlik Kuramları (Sağlık Yönetimi Bakış Açısıyla). Konya: Eğitim Yayınevi.

Aycan, Z. (2001). Paternalizm: Yönetim ve Liderlik Anlayışına İlişkin Üç Görgül Çalışma, Yönetim Araştırmaları Dergisi, 1(1): 1-19.

Aycan, Z. (2006). Paternalism: Towards Conceptual Refinement and Operationalization. In K. S. Yang, K. K. Hwang, \& U. Kim (Eds.), Indigenous and cultural psychology: Understanding people in context (pp. 445-466). New York: Springer.

Bağdatlı, F. (2015). Okul Yöneticilerinin Çatışma Yönetimi Stilleri ile Örgüt Kültürü Arasındaki Ilişski, Yayınlanmamış Yüksek Lisans Tezi, İstanbul Sabahattin Zaim Üniversitesi, İstanbul.

Bökeoğlu, Ö, Ç. ve Yılmaz, K. (2008). İlköğretim Okullarında Okul Kültürü Hakkında Öğretmen Görüşleri, Kuram ve Uygulamada Eğitim Yönetimi, 54: 211- 233.

Büyüköztürk, Ş., Çakmak, K., Akgün, E.A., Karadeniz Ş. ve Demirel, F. (2015). Bilimsel Araştırma Yöntemleri (18. Baskı). Ankara: Pegem A Yayıncılık.

Cerit, Y. (2012). Paternalistik Liderlik ile Yöneticiden ve İşin Doğasından Doyum Arasındaki İlişki. Ondokuz Mayıs Üniversitesi Eğitim Fakültesi Dergisi, 31(2).

Cerit, Y., Özdemir, T. ve Akgün, N. (2011). Sınıf Öğretmenlerinin Okul Müdürlerinin Paternalist Liderlik Davranışları Sergilemelerini İstemeye Yönelik Görüşlerinin Bazı Demografik Değişkenler Açısından İncelenmesi. AïBÜ Eğitim Fakültesi Dergisi, 11(1). 
Cesur, D. K. (2015). Paternalist Liderlik ve Örgüt Kültürü Illişkisi, Yayınlanmamış Yüksek Lisans Tezi, Sakarya Üniversitesi, Sakarya.

Cesur, D. K., Erkilet, A., ve Taylan, H. H. (2015). Paternalist liderlik ve örgüt kültürü ilişkisi: Sakarya Üniversitesi örneği. Akademik İncelemeler Dergisi, 14(1): 87-116.

Conn, S. J. (2004). Exploring the Relationship Between Perceptions of Trust and Perceptions of Organizational Justice in a Geographically Dispersed Organization. Psychology, Business Administration Management (0454).

Coşgun, M. (2012). Popüler Kültür ve Tüketim Toplumu. Batman University Journal of Life Sciences, 1(1).

Çelik, V. (2002). Okul Kültürü ve Yönetimi. Ankara: Pegem Yayıncılık.

Çelik, V. (2007). Eğitimsel Liderlik. (4. Baskı). Ankara: Pegem A Yayıncılık.

Çokluk, Ö., Şekercioğlu, G. ve Büyüköztürk, Ş. (2012). Sosyal Bilimler için Çok Değişkenli İstatistik: SPSS ve LISREL Uygulamaları. Ankara: Pegem Akademi Yayınları.

Dağlı, A. and Ağalday, B. (2017). Developing A Headmasters' Paternalistic Leadership Behaviours Scale in Turkey. Journal of Education and Practice, 8(30): 190-200

Demirer, P. (2012). Is Paternalistic Leadership Empowering: A Contingency Framework, Yayınlanmamış Yüksek Lisans Tezi, Koç Üniversitesi, İstanbul.

Dinçer, Ö. (1992). Örgüt Geliştirme:(Teori, Uygulama ve Teknikler). Marmara Üniversitesi İktisadi ve İdari Bilimler Fakültesi.

Dönder, H. H. (2006). Öğretmenlerin Örgütsel Vatandaşlık Davranışları ve Bürokrasi, Yayınlanmamış Yüksek Lisans Tezi, Kocatepe Üniversitesi, Afyon.

Erben, G.S. (2004). Toplumsal kültür aile kültürü etkileşimi bağlamında paternalizm boyutuyla işletme kültürü: Türkiye örneği. 1. Aile İşletmeleri Kongresi, 17-18 Nisan 2004, İstanbul Kültür Üniversitesi Yayınları Kongre Kitabı: 345-356.

Erben, G. S., and Güneşer, A. B. (2008). The Relationship Between Paternalistic Leadership and Organizational Commitment: Investigating The Role of Climate Regarding Ethics. Journal of Business Ethics, 82(4): 955-968.

Erkuş, A., Tabak, A., ve Yaman, T. (2010). Paternalist (babacan) liderlik çalışanların örgütsel özdeşleşmelerini ve işten ayrılma niyetlerini etkiler mi? Bir özel hastane uygulaması. 9. Ulusal İşletmecilik Kongresi, Zonguldak.

Esinbay, E. (2008). İlköğretim Okullarında Örgüt Kültürü (Balıkesir İli Örneği), Yayınlanmamış Yüksek Lisans Tezi, Balıkesir Üniversitesi, Balıkesir.

Fahr, J. L. and B. S. Cheng (2000). A Cultural Analysis of Paternalistic Leadership in Chinese Organizations. J.T.Li, A.S.Tsui and E.Walton (Ed.). Management and Organizations in Chinese Context. London: Macmillan, 84-127.

Fırat, N. (2007). Okul Kültürü ve Öğretmenlerin Değer Sistemleri, Yayınlanmamış Doktora Tezi, Dokuz Eylül Üniversitesi, İzmir.

Fieldler, E. F. (1967). A Theory of Leadership Effectiveness. New York: McGraw-Hill Book Company.

Gerçek, M. (2018). Yöneticilerin Babacan (Paternalist) Liderlik Davranışlarının Psikolojik Sözleşme Bağlamındaki Beklentileri Üzerindeki Etkilerine Yönelik Bir Çalışma. Eskişehir Osmangazi Üniversitesi IBBF Dergisi, 13(2): 101-118 
Gümüşeli, A.İ. (2001). Çağdaş Okul Müdürünün Liderlik Alanları. Kuram ve Uygulamada Eğitim Yönetimi, 28, 531-548.

Günbayı, İ. (2014). Örgütsel Kültür ve Okul İklimi, (Editör) Çelikten, M. ve Özbaş, M.: Eğitim Yönetimi içinde (ss.177-194) İstanbul: Lisans Yayıncllık.

Hersey, H., and Blanchard, K. (1982). Management of Organizational Behavior: Utilizing Human Resources. New Jersey: Prentice-Hall.

https://beylikduzu.meb.gov.tr> [Erişim Tarihi: 20.05.2019]

İbicioğlu, H., Özmen, H. İ., ve Taş, S. (2009). Liderlik Davranışı ve Toplumsal Norm İlişkisi: Ampirik Bir Çalışma. Süleyman Demirel Üniversitesi İktisadi ve İdari Bilimler Fakültesi Dergisi, 14(2).

Koçman, E. A. (2003). Illköğretim Okul Müdürlerinin Vizyoner Liderlik Davranışları ve Okul Kültürü, Yayınlanmamış Doktora Tezi, Dokuz Eylül Üniversitesi, İzmir.

Korkmaz, F., Gökdeniz, İ., ve Zorlu, K. (2018). Paternalist Liderlik Davranışının Örgütsel Özdeşleşme Üzerindeki Etkisinde Çalışanların İşe Tutkunluk Düzeylerinin Aracılık Rolü. İşletme Araştırmaları Dergisi, 10(3): 950-973.

Koşar, S. (2008). Illköğretim Okulu Yöneticilerinin Yönetimde Gücü Kullanma Stilleri ile Örgüt Kültürü Arasındaki İlişki, Yayınlanmamış Yüksek Lisans Tezi, Gazi Üniversitesi, Ankara.

Koşar, S., ve Çalık, T. (2011). Okul yöneticilerinin yönetimde gücü kullanma stilleri ile örgüt kültürü arasındaki ilişki. Kuram ve Uygulamada Ĕ̆itim Yönetimi, 4(4): 581-603.

Köksal, O. (2011a). Bir Kültürel Liderlik Paradoksu: Paternalizm. Mustafa Kemal Üniversitesi Sosyal Bilimler Enstitüsü Dergisi, 8(15):101-122.

Köksal, O. (2011b) Paternalizm ile Algılanan Örgütsel Adalet Arasındaki İlişkinin Tespitine Yönelik Bir Araştırma, C.Ü., İktisadi ve İdari Bilimler Dergisi, 12(2): 159-170.

Kurşun, A. T. (2019). Okul Kültürünün İncelenmesi: Bir Meta Analiz Çalışması, Yayınlanmamış Doktora Tezi, Necmettin Erbakan Üniversitesi, Konya.

Kurt, İ. (2013) Paternalist liderlik ile çalışanların işlerine yaratıcı katılım algıları arasındaki ilişkiyi araştırmaya yönelik bir çalışma. Yeditepe Üniversitesi, Sosyal Bilimler Enstitüsü, Sosyal ve Beşeri Bilimler Dergisi, 5(1): 321-330.

Mete, Y.A. ve Serin, H. (2015). Okul Yöneticilerinin Babacan Liderlik Davranışı ile Öğretmenlerin Örgütsel Vatandaşlık ve Örgütsel Sinizm Davranışları Arasındaki İlişki. Hasan Ali Yücel Eğitim Fakültesi Dergisi,12(24): 147-159.

Nal, M. (2018). Sağlık Yöneticilerinin Paternalist Liderlik Davranışlarının Çalışanların İş Doyumu ve Örgütsel Adalet Algısı İlişkilerinin İncelenmesi, Yayınlanmamış Doktora Tezi, Marmara Üniversitesi, İstanbul.

Önen, S. M., ve Kanayran, H. G. (2015). Liderlik ve Motivasyon: Kuramsal Bir Değerlendirme. Birey ve Toplum Sosyal Bilimler Dergisi, 5(2): 43-64.

Önsal, A. (2012). Okul Müdürlerinin İletişim Becerileri ile Okul Kültürü Arasındaki İlişki, Yayınlanmamış Yüksek lisans tezi, Maltepe Üniversitesi, İstanbul.

Özdemir, A. (2006). Okul Kültürünün Oluşturulması ve Çevreye Tanıtılmasında Okul Müdürlerinden Beklenen ve Onlarda Gözlenen Davranışlar. Türk Eğitim Bilimleri Dergisi, 4(4): $411-433$ 
Özdemir, S. (2013). İlköğretim Okullarında Okul Kültürü ile Örgütsel Sağlık Arasındaki İlişki. Kuram ve Uygulamada Eğitim Yönetimi, 4(4): 599-620.

Özer, F. ve Yurdun, A. (2012). Birleşme/Devir Alma Süreci Yaşayan Örgütlerde Paternalist Liderlik Tipinin İşten Ayrılma Niyeti Üzerine Etkileri. Organizasyon ve Yönetim Bilimleri Dergisi, 4(2): 71-80.

Özer, N. ve Akbaş, M. (2016). Ortaokul Öğretmenlerinin Okul Kültürü Profili ve Örgütsel Güvene İlişkin Algıları Arasındaki İlişki. Milli Ĕ̆itim Dergisi, 45(211): 63-86.

Sarp, P., Kumral, T. ve Bozkurt, S. (2019). Babacan Liderlik ve İşte Var Olamama İlişkisinde İş Güvencesinin Aracı Rolü. Selçuk Üniversitesi Sosyal Bilimler Enstitüsü Dergisi, (41): 161-168.

Schein, E. H. (2004). Organizational culture and leadership (3nd ed.). San Francisco: Jossey-Bass.

Schooley, M. L. (2005). An analysis of the relationship between transformational leadership and school culture (Doctoral dissertation). University of Missouri, Columbia.

Sezgin, F. (2010). Öğretmenlerin Örgütsel Bağlılığının Bir Yordayıcısı Olarak Okul Kültürü. Eğitim ve Bilim, 35(156): 142-159.

Sökmen, A. (2013). Örgütsel davranış. Ankara: Detay Yayıncıllk.

Şahin, G. S. (2015). The Relationship Between Mobbing and Paternalistic Leadership: Perception of Generation y's., Unpublished Master's Thesis, Middle East Technical University: Ankara.

Şendoğdu, A. A. ve Erdirençelebi, M. (2014). Paternalist Liderlik ile Örgütsel Vatandaşlık Davranışı Arasındaki İlişkiye Yönelik Bir Araştırma. Sosyal ve Ekonomik Araştırmalar Dergisi, 27: 253-274.

Şimşek, Y. (2003). Okul Müdürlerinin İletişim Becerileri ile Okul Kültürü Arasındaki İlişki (Eskişehir İli Örneği), Yayınlanmamış Doktora Tezi, Anadolu Üniversitesi, Eskişehir.

Şişman, M. (1994). Örgüt kültürü̈:(Eskişehir il merkezindeki ilkokullarda bir araştırma). Anadolu Üniversitesi.

Şişman, M. (2002). Örgütler ve Kültürler. Pegem A Yayıncllık.

Tanrıöğen, Z. M., Baştürk, R. ve Başer, M. U. (2014). İlköğretim Okullarında Cinsiyet ve Örgütsel Rollere Göre Örgüt Kültürü Alg1sı. Trakya Üniversitesi Eğitim Fakültesi Dergisi, 4(1): 170-180.

Taşlıyan, M., Çiçeklioğlu, H., ve Bıyıkbeyi, T. (2017). Paternalist Liderlik ve Örgütsel İletişim Arasındaki İlişki: Doğu Akdeniz Bölgesinde Bir Belediye Örneği. Assam uluslararası hakemli dergi, 4(8): 70-87.

Terzi, A. R. (2000). Örgüt Kültürü, Ankara: Nobel Yayın Dağıtım.

Terzi, A.R. (2005). İlköğretim Okullarında Örgüt Kültürü. Kuram ve Uygulamada Eğitim Yönetimi, 43(43): 423-442.

Turan, S. ve Bektas, F. (2013). The Relationship Between School Culture and Leadership Practices. Eurasian Journal of Educational Research, 52: 155-168.

Tutar, H. (2016). Örgütsel Davranış. İstanbul: Detay Yayıncılık

Uçar, Z. (2019). Lider Üye Etkileşimi Lensinden Paternalist Liderlik ve İş Tatmini İlişkisi, BEÜ AID, 4(1): 28-49.

Yalçın, M. and Karadağ, E. (2013). Servant leadership and school culture: a structural equation modelling. Inonu University Journal of the Faculty of Education 14(2): 101-120. 
Yalınkılıç, D. (2012). Öğretmen Alg̨larına Göre İlköğretim Okulu Müdürlerinin Liderlik Davranışları ile Örgüt Kültürü Arasındaki İlişki, Yayınlanmamış Yüksek Lisans Tezi, Maltepe Üniversitesi, İstanbul.

Yaman, T. (2011). Yöneticilerin Paternalist Lider Davranışlarının Çalışanların Örgütsel Özdeşleşmelerine, İş Performanslarına ve İşten Ayrılma Niyetlerine Etkisi: Özel Sektörde Uygulama, Yayınlanmamış Yüksek Lisans Tezi, Kara Harp Okulu, Ankara.

Yardımcı, C. (2010). Paternalistik Liderlik Davranışlarının İş Tatmini Üzerindeki Etkisi: Bankacılık Sektörü Üzerinde Bir Uygulama, Yayınlanmamış Yüksek Lisans Tezi, Hacettepe Üniversitesi, Ankara.

Yurdun, Ö. A. (2011). The Relationship Between Mobbing and Organizational Commitment and The Moderating Role of Paternalistic Leadership, Yayınlanmamış Yüksek Lisans Tezi, Marmara Üniversitesi, İstanbul.

Zel, U. (2011). Kişilik ve Liderlik. Ankara: Nobel Yayıncılık. 